International Journal of Current Advanced Research

ISSN: O: 2319-6475, ISSN: P: 2319 - 6505, Impact Factor: SJIF: 5.995

Available Online at www.journalijcar.org

Volume 6; Issue 4; April 2017; Page No. 3509-3514

DOI: http://dx.doi.org/10.24327/ijcar.2017.3514.0305

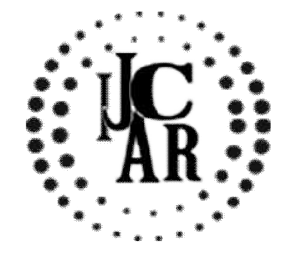

Research Article

\title{
DOES EXERCISES IMPROVE SLEEP QUALITY, BALANCE AND STRENGTH AMONG FEMALES
}

\section{Monika Rani*., Jaspreet Kaur., Taruna Singal., Manoj Malik and Arpit Bansal}

Department of Physiotherapy, Guru Jambheshwar University of Science \& Technology, Hisar

\begin{tabular}{l}
\hline A R T I C L E I N F O \\
\hline Article History: \\
Received $6^{\text {h }}$ January, 2017 \\
Received in revised form $10^{\text {th }}$ February, 2017 \\
Accepted $15^{\text {th }}$ March, 2017 \\
Published online $28^{\text {th }}$ April, 2017 \\
\end{tabular}

Key words:

Sleep Quality, Balance, Strength, Core Muscles, Core Exercises

\begin{abstract}
A B S T R A C T
Background and Purpose: there are several physical and psychological changes that occur with normal aging e.g. muscle weakness, balance disorder and disturbances in sleep. Aging starts early in the 30's leading to various musculoskeletal disorders.

So the purpose of our study is to prevent elders from these effects of aging by doing pilates, Swissball exercises in middle age group.

Design: Comparative Experimental Study Design

Participants: N= 40; Age range $=30-60$ yr: 20 in Group A, 20 in Group B

Intervention: Pilates exercise (floor mat) in Group A, exercise given on Swissball in Group B.

Main Outcome Measures: balance was assessed by Four Square Step Test, sleep quality was assessed by Pitts Burgh Sleep Quality Index and strength was assessed by Back Leg Chest Dynamometer

Result: there was significant increase in balance and strength in the Pilates group and significant increase in sleep quality, balance and strength in Swissball exercise group. But when two groups were compared there was no significant difference.

Conclusion: this study has shown that in healthy middle aged individuals both exercises shows significant improvement in the sleep quality, balance, strength in both groups but none of the group showed superior benefits.
\end{abstract}

Copyright $₫ 2017$ Monika Rani et al. This is an open access article distributed under the Creative Commons Attribution License, which permits unrestricted use, distribution, and reproduction in any medium, provided the original work is properly cited.

\section{INTRODUCTION}

Aging is an irreversible biological process, a man ages continuously throughout his life. But now a days the longevity of life increases (Bhattacharya, P. 2005). According to public health care system, per capita health expenditure is 5.5 times higher for older people than middle aged individuals (Granacher, Urs, et al 2012). Several physical and psychological changes are known to occur with normal aging. Changing in sleep quality occurs due to increasing age. It may be subjective or objective. Subjectively older adults report waking up at earlier times, increased sleep onset latency, time spent in bed, night time awakening and napping and decreased total sleep. Objectively sleep disturbances observed were the time spent in lighter stages of sleep increased while time spent in rapid eye movement sleep and slow wave sleep decreased. Mostly in older adults, 3 most common sleep disorders occur. These are sleep disordered breathing, restless leg syndrome/ periodic limb movement in sleep and rapid eye movement sleep behaviour disorder. Some studies suggests these sleep disturbances occur due to medical conditions e.g. chronic pain, diabetes mellitus, arthritis etc, depression and

*Corresponding author: Monika Rani

Department of Physiotherapy, Guru Jambheshwar

University of Science \& Technology, Hisar certain drugs e.g. beta blockers, bronchodilators, corticosteroid, diuretics etc (Krems, C., et al 2004). According to medical records elders have increase risk of fall due to impaired balance. With aging balance are impaired due to several changes occurs in the visual, vestibular, sensory and motor functions (J. Holviala, et al 2012), (Claude P. Hobeika 1998). Degenerative macular and ocular changes occur with age which leads to decrease visual acuity. In vestibular system there is significant loss in hair cells alongwith decrease primary vestibular neurons. In cerebral cortex there is decrease neuronal cell density observed and in cerebellum, decrease in purkinje cell takes place which leads to auditory impairments. As the age growns there are degenerative changes occurs in sensory and motor systems especially in lower limb (Claude P. Hobeika 1998). Which cause decrease in muscle strength and postural instability which leads to impaired balance (J. Holviala, et. al. 2012). There are 2 main factors which also lead to increased risk of falling. These are extrinsic factors (e.g. gloose rugs, lightening, obstructive walkways) and intrinsic factors (e.g. muscle weakness, balance and gait disorders) (Granacher, Urs, et al 2012). Biologic aging as well as physical inactivity results in decreases in maximum isometric, concentric and eccentric forces, rate of force development as well as muscle power. Most specifically the capacity to generate force rapidly 
declines at a faster rate than the ability to produce maximum strength (Granacher, Urs, et al 2012). Peoples who are having 30-60 year of age do lesser activity and are reported joint and muscle strength changes in typically ageing population (Krems, C., et al 2004); (Nitz, J., \& Choy, N. 2004); (Pober, D., et al. 2002). Mostly at the age of $70 \mathrm{yr}$ there is decrease in static and dynamic strength seen with reduced muscle mass. This may be occur due to decrease in number of spinal motor neuron, degenerative changes occur at motor end plate, spinal nerve root and peripheral nerves and sprouting of axons. In old age muscle weakness occurs due to loss of muscle fibres or decrease in number of functioning motor unit, reduction in fibre size and loss of fast twitch muscle fibres. Along with all these there are also atrophy in muscle fibres, angulations of fibres and necrosis of muscle fibres with cell infiltration are also observed in higher age group individuals (Rays Marks 1992). Difference in balance performance were already apparent among young (30-39 yr), middle aged (40-49 yr) is more after age of $60 \mathrm{yr}$ (Granacher, Urs, et al 2012). Most of the researcher supports the functional changes that occur with ageing as it starts early in the 30's. So we should focus on middle aged adults to stop these functional changes that affect health. Many strategies to improve functional dysfunction have included specific balance training strategies, strength training, walking, Tai Chi and multi dimensional exercises. Few intervention, however, have showed consistent positive outcomes in balance (Rhonda Orr, et. al. 2006). In the present study pilates and swiss ball exercises have been primarly incorporated. Currently there are several different styles of Pilates that can be used now a day. There are several published claims that Pilates exercises strengths the core, increases flexibility and improves posture and balance (Curnow, D., et. al. 2009). The aim of Instability training is to improve neuromuscular adaptations, decrease in the risk of injury, increase in coordination, and increase in balance, stability and proprioceptive capabilities rather than to gain strength (Behm, D.G. \& Anderson, K.G 2006). By improving dynamic postural control and balance, producing more coordinated and consistent movement pattern during movement, injuries may be prevented (Verhagen, E.A.L.M., et. al. 2005).

\section{METHOD}

Study Design: A Randomised Comparative Experimental study was designed. Volunteers were randomly divided into either Pilates or Swiss ball exercise group. The duration of the study was 4 weeks. The dependent variables were dynamic balance, strength and sleep quality. All the variables were recorded pre and post intervention. Instruments for testing were calibrated and used by the same researcher to control possible inter tester variation. Prior to the variation are standardized $5 \mathrm{~min}$ warm up was completed. Participant joined a 4 week series of $1 \mathrm{hr}$ Pilates or Swiss ball exercise 6 times per week.

Sample selection: A sample of 40 subjects both male and female having 30-60 age group were recruited from GJU S\&T, Hisar. Of these 20 were located to Pilates group and 20 were allocated to pilates group and 20 were in Swiss ball exercise group (protocol in fig 1).

Subjects were included if they were independently living in the residential house. Exclusion criteria were general health problem or orthopaedic problem that would affect their full participation in intervention protocol and lead to the inability to attend at least $80 \%$ of all training session, self reported neurological disorders (i.e. Parkinson, multiple sclerosis, head injury, peripheral neuropathy, stroke, vestibular disorders), cognitive impairment, medication which causes unsteadiness (sedatives, antidepressent and hypnotics), self reported musculoskeletal disorders (i.e. joint replacement, amputation or physically liming arthritis).

Test description and measures: prior to testing a standardized 5 minute warm up was completed. After completion of warm up patient underwent the Four Square Step Test is a test of dynamic balance. It includes a stopwatch and four canes. The square is formed by using four canes resting flat on floor. Canes were $90 \mathrm{~cm}$ long. The subjects stand in square no 1 facing squares no 2 . The aim is to step as fast as possible into each square in 2,3,4,1,4,3,2 and 1 sequence. The score is recorded as the time taken to complete the sequence. The stopwatch starts when the first foot contact the floor in square 2 and finishes when the last foot comes back to touch the floor in square 1. 2 FSST readings were completed with the best time taken as the score. According to Dite and Temple (2008), who perform the test less than 15 second was considered to be non multiple fallers (Wayne Dite, \& Viviene A. Temple 2002); (Susan L. et. al. 2007).

Readings for sleep quality was done using Pitts Burgh Sleep Quality Index. It consists of 19 self reported items indicates of subscales: subjective sleep, efficiency, sleep latency, sleep duration, sleep quality, sleep disturbance, sleep medication used and day time dysfunction due to sleepiness interfered with their sleep on a 4 point Likert type scale $(0=$ not at all, $3=$ three or more times a week). A PSQI total score of $>5$ is indicative for poor sleep (Adam P. Spira, et. al. 2012); (Sherry A. Beaudreau, et. al. 2012) Lastly strength was measured using Back- Leg-Chest Dynamometer. The body would be inclined forward at an angle of 60 degree for measurement of strength. The strength was recorded on the dial of the dynamometer as the best of the three trails in kilogram. A $30 \mathrm{~s}$ time interval separated each strength testing (Bethards, Suzy, \& Everitt- Smith, et. al. 1995).

Data collection: instrument for testing all variables were calibrated and used by the same researcher to control possible inter observer variation. Prior to testing, a standardized $5 \mathrm{~min}$ warm up was completed. Then intervention was given in form of pilates and swiss ball exercise and for 4 weeks, 5 days a week. All measurements were taken again after completion of 4 weeks study.

Treatment description: subjects after been explained the purpose; course, benefit and possible dangers of the study signed informed consent. Pre test sleep quality, balance and strength were assessed by PSQI, FSST and Dynamometer respectively. Group A Pilates exercise given on floor mat. Group B exercises given on Swiss ball. Patients in both the group were assessed for sleep quality, balance and strength on $1^{\text {st }}$ day and end of $4^{\text {th }}$ week. Subjects were instructed to do warm up exercises for 5 minutes which consisted of relaxation and stretching exercises, followed set of exercises planned for respective Pilates or Swiss ball group. Both the groups were asked to perform cooled down exercises for 5 min which consisted of relaxation and stretching exercises performed during warm up. Exercise protocol was started as explained in Table 1. 
Table 1 treatment session and exercise protocol

\begin{tabular}{|c|c|c|}
\hline Session & Pilates group & Swiss ball exercise group \\
\hline Warm up & $\begin{array}{l}\text { standing roll down, hamstring stretch, spiral stretch, thigh stretch, calf } \\
\text { stretch, baby pose }\end{array}$ & $\begin{array}{l}\text { seated bounce on ball, seated leg rotation, inner thigh stretch, } \\
\text { combination stretch, lumbar rotation, seated pelvic rotation, } \\
\text { hamstring stretch, ball reach and back flex, cat and camel }\end{array}$ \\
\hline $1^{\text {st }}$ week & $\begin{array}{c}\text { abdominal preparations, bridging, single leg stretch, rolling like a ball, } \\
\text { obliques, knee fall out, roll back, side kick series }\end{array}$ & $\begin{array}{l}\text { abdominal crunch basics, bridging, flutter version, press up or } \\
\text { kneeling on floor, kneeling back extension, squat against wall }\end{array}$ \\
\hline $2^{\text {nd }}$ week & $\begin{array}{c}\text { abdominal preparation at } 90 \text {, single leg breeding, half roll back with twist, } \\
\text { side kick series, obliques at } 90 \text { degree, double leg stretch, seal, prone } \\
\text { supermen }\end{array}$ & $\begin{array}{c}\text { bridging, press up with ball under thigh, flutter version } 2 \text {, } \\
\text { hamstring curl, back extension with toes on the floor, squat and } \\
\text { ball hold }\end{array}$ \\
\hline $3^{\text {rd }}$ week & $\begin{array}{l}\text { spine stretch forward, hundred, roll up, swimming arm, open leg rocker, } \\
\text { hip roll, all four balance, front plank at } 8 \text { times }\end{array}$ & $\begin{array}{l}\text { single leg bridging, pike, latissimus ball roll, press up toes on the } \\
\text { ball, single leg squat against wall, single leg hamstring curls, } \\
\text { plank, weighted abdominal curl, flutter version } 3 \text { at } 8 \text { times }\end{array}$ \\
\hline $4^{\text {th }}$ week & $\begin{array}{l}\text { spine stretch forward, hundred, roll up, swimming arm, open leg rocker, } \\
\text { hip roll, all four balance, front plank at } 10 \text { times }\end{array}$ & $\begin{array}{l}\text { single leg bridging, pike, latissimus ball roll, press up toes on the } \\
\text { ball, single leg squat against wall, single leg hamstring curls, } \\
\text { plank, weighted abdominal curl, flutter version } 3 \text { at } 10 \text { times }\end{array}$ \\
\hline
\end{tabular}

Statistical Analysis: dependent t Test was used to find out the significance with in the same group with the values of the parameters means between balance, strength and sleep quality. Independent $t$ test was used to find out the significance between the groups means Pilates and Swiss ball exercise group.

\section{RESULT}

After the treatment session the outcome measures were documented. When pre intervention readings were compared to post intervention readings marked improvement was observed in balance and strength and no improvement was observed in sleep quality in Pilates group (table 2). Whereas in Swiss ball exercise group marked improvement was observed in sleep quality, balance and strength (table 2). But no improvement was observed in sleep quality, balance and strength in which pilates and swiss ball group were compared (table 3).

Table 2 pre and post intervention data of pilates and swiss ball exercise group

\begin{tabular}{ccccccccc}
\hline \multirow{2}{*}{ Variables } & \multicolumn{2}{c}{ mean \pm SD (pilates group) } & \multicolumn{2}{c}{ mean \pm SD (swiss ball ex group) } & \multicolumn{2}{c}{ t-value } & \multicolumn{2}{c}{ Significance } \\
\cline { 2 - 7 } & Pre & Post & Pre & Post & Pilates & Swiss ball & Pilates & Swiss ball \\
\hline Sleep quality & $6.3 \pm 2.49$ & $5.6 \pm 2.32$ & $5.35 \pm 2.13$ & $4.6 \pm 1.87$ & 1.47 & 2.38 & NS & S \\
Balance & $11.2 \pm 1.78$ & $9.25 \pm 1.27$ & $10.89 \pm 2.5$ & $8.59 \pm 1.14$ & 7.83 & 5.4 & HS & HS \\
Strength & $133.4 \pm 58.54$ & $156.5 \pm 57.47$ & $127.75 \pm 70.98$ & $158.5 \pm 65.51$ & 5.86 & 5.66 & HS & HS \\
\hline
\end{tabular}

Table 3 comparison between pilates and swiss ball exercises group

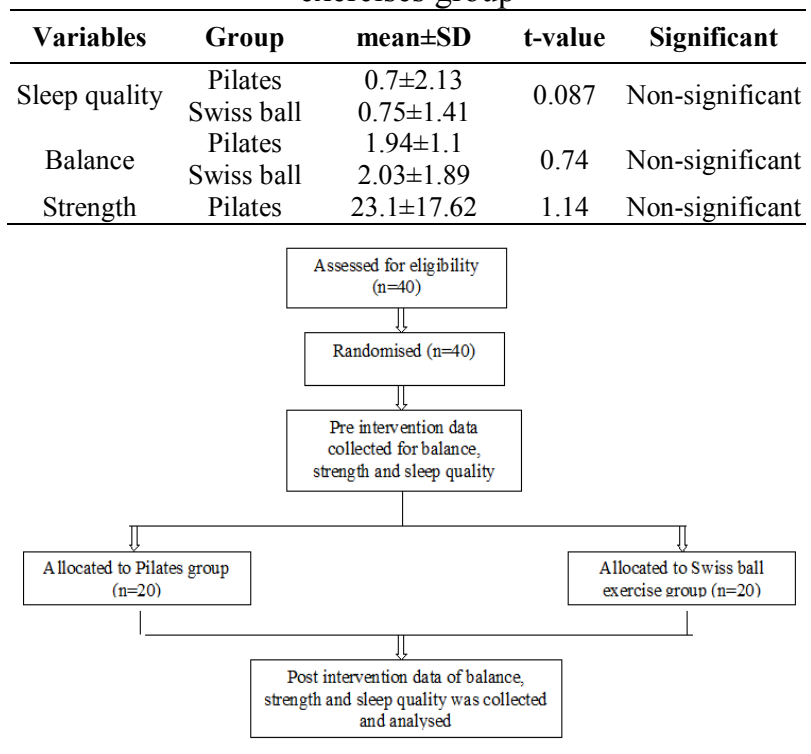

Fig 1 protocol of the study

\section{DISCUSSION}

In this study, total 40 subjects were selected and assigned randomly to 2 groups of 20 subjects each who received Pilates and Swiss ball training for 4 weeks. The 2 groups were analyzed with sleep quality, balance and strength parameters for the statistical analysis. To our knowledge, this study seems to be the first objective investigations of the comparison between Pilates and Swiss ball training for parameters, sleep quality, balance and strength among middle aged and old age healthy individuals. The values showed significant increase in balance and strength in the Pilates group at $\mathrm{p}<0.05$. The value showed significant increase in sleep quality, balance and strength in Swiss ball group at $\mathrm{p}<0.05$. But when the both groups were compared as to find out whether any of the group show superior benefits for improvement in sleep quality, balance and strength there was no significant difference.

Hence the null hypothesis of the study could not be rejected stating that Pilates and Swiss ball training have no significant effect in improving the sleep quality, balance and strength among healthy middle aged. The result of present study indicates that both Pilates and Swiss ball training are good option for rehabilitation of aged individuals. Research increasingly demonstrates associations between sleep disturbances and poor health outcomes, including fall, medical morbidity, psychiatric symptoms, and cognitive impairment. Considering the impact of sleep disturbances on health. It is important to pay special attention to sleep quality among adults. Caldwell et al. show that the Pilates promot self efficacy, positive mood and sleep quality, making this method a better choice than Taiji quan and recreation (Caldwell, K. et al 2009). These health outcomes are psychological in nature. The physicality of the Pilates may contribute to improvement outcomes in this study. In present study we did not found any significant improvement in sleep quality in Pilates groups. This may be due to experiment error as we did not control the variance of extraneous variables. We could not find any evidence in literature review supporting that Swiss ball training improves sleep quality. In our study, contradictory results were found that subjects in Swiss ball training group improved sleep quality. This may be as a result 
of physical changes due to exercise and time of training. This question needs to be further investigated. Optimal control of balance in upright posture is an essential requirement for support, daily activity or for prevention of injury. Stabilization of postural equilibrium is achieved by continuous interaction between afferent and efferent system with feedback from somato-sensory and visual system. Research supports strengthening exercises contributes to better balance and gait. In present study both balance and strength improves significantly in both groups, neither Pilates nor Swiss ball on intergroup comparison show any superior benefits in improving balance and strength. Pilates based exercise challenges the efferent and afferent system while focusing on principles of breathing, control, centering, precision, concentration and flow (Brent D. Anderson, Spector, A.). Johnson et al. demonstrated that healthy subjects who participated in Pilates based exercises had significant improvement in dynamic balance as measured by FRT (Eric G. Johnson, et al 2007). Benefits were found in static balance in Rodrigues et al. investigation, where as Kloubec did not observed any differences. Such differences may be because of the measuring devices and type of intervention. Rodrigues used the Tinetti test and intervention was based on supervised Pilates on the apparatus. Kloubec used a balance board, and intervention consisted of supervised Pilates on the mat. Thus, the contradictory findings may be because of differences in surface (stable vs unstable) and equipment (Pilates vs mat) (Rodrigues B. Cader, S. Dantas, E. 2010); (Kloubec, June A 2010). When considering the mechanism resulting in improvement of body balance after Pilates exercise, strengthening of trunk and peri pelvic muscles in sense of the "powerhouse" appears an over simplified mechanistic approach, as the functioning of other systems might also be positively influenced by the Pilates exercises. Since impairments of proprioception have been described for elderly and are held at least in part responsible for the increased risk of falls, exercises aimed at stimulating the kinesthetic sense should be recommended for older population. Swiss ball exercises maintain balance and body position by stimulating proprioceptors and provide feedback (Soderman, K. Werner,. et. al. 2000); (Verhagen E.A.L.M.,. et. al. 2005). Swiss ball provides unstable condition that causes changing in muscletendon unit length, tension and neuromuscular activity, which challenge the ability to detect (propioception) and to respond (efferent activity) to changes in balance (Anderson, K.G. \& Behm, D.G. 2005) (Heitkamp HC, et. al.2001); (Magnusson, SP. et. al. 1997). The use of close kinetic chain exercise such as squats on Swiss balls and crunches involve multi joint and multi plane movements that facilitate the integration of proprioceptors which are responsible for joint direction and position (Rogol, I. Ernst \& G. Perrin, D. 1998). Balance training can increase the sensitivity of the feedback pathway, shorten onset times and improve sensitivity of the position sense. Increased co-contractile activity can improve motor control and balance (Engelhorn, R. 1983) that helps to control the limb position when introducing force (Behm, D.. et.al. 2010). The trunk musculature stabilizes the spine during normal movements and motor control contributing to dynamic control. In our study both Pilates and Swiss ball group showed significant improvement in strength. Both Pilates and Swiss ball exercises engage the global and local stabilizers of spine, thus the result of study are justified at the physiological basis. Kate and Gibson researched to the "effect of 8 weeks mat Pilates training program" and they found significant improvement in body composition, flexibility and muscle strength (Rogers, K. and Gibson, A. 2009). Contradictory results were found for abdominal strength, for which improvement were observed by Sekendiz et al. Sekendiz et al. demonstrated improvement in abdominal strength but no improvement were found in Donahoe-Fillmore et al. such differences may be because of measuring abdominal strength (maximum curl-ups vs isometric contraction respectively), Pilates equipments method (private Pilates method on the mat and apparatus vs unsupervised Pilates method on the mat, respectively) and the duration of the Pilates method intervention (12 vs 10 weeks respectively) (DonahoeFillmore B, et. al. 2007); (Sekendiz B, et al. 2007). Behm et al. studied agonist/antagonist relationships of the leg extensors with instability. During leg extension, antagonistic hamstring activity increased by $29.1 \% \quad(\mathrm{p}=0.05)$ under unstable versus stable conditions (Behm D, Anderson $\mathrm{K}$, et al 2002). Vera-Garcia et al. tested the type of surface (stable or unstable) on the muscle mechanics of the abdominal wall. They indicated that performing curl-up exercises on an unstable surface increased abdominal muscle activity. EMG analysis show rectus abdominal muscle activity on a stable surface was $21 \%$ of the MVC and external oblique muscle activity was demand on the motor control system when performing abdominal exercises on labile equipment (VeraGarcia F, Grenier S, Mc Gill S. 2000). While performing exercises on an unstable surface, the motor control system initiates the co-activation of both global and local muscles to stabilizes the spine and maintain balance (Caroline, M. Stretton Nancy, K. Latham Kristte, N. 2006). The greater activation had recruits of both global and local muscles with unstable training could lead to meaningful trunk strength by improving motor control and a spectrum of muscle activation.

\section{Limitations}

- This study was limited to only healthy middle aged individuals.

- The study was done for one time; longer duration exercise protocols may show better results.

\section{Suggestion \& Further Recommendation}

- It would be interesting to assess how long improvement would be maintained by adding a delayed post test.

- This type of intervention should be applied in neurological impairments like stroke, spinal cord lesion, multiple sclerosis and cerebral palsy.

- More research should be done on still older age group of patients to see how they fare by this treatment.

- The improvement in balance reaction can be better judged using platforms.

\section{CONCLUSION}

This study has shown that in healthy middle aged individuals of age group 30-60 years, Pilates and Swiss ball training for a duration of 60 minutes once a day, 6 days for 4 weeks had a significant improvement in the sleep quality, balance and strength in both groups and none of the exercise group showed superior benefits over the other exercise group. 


\section{Acknowledgement}

We are highly thankful to all subjects who voluntarily participated in the study. We also thank department of physiotherapy, GJU S\&T, Hisar for using the assessts so that, the study could run smoothly.

\section{Declaration of interest}

There was no declaration of interest. There was no conflict of interest among any of the authors whatsoever. The information contained in the manuscript and related files is not submitted to any other journal in any other form, by any of the authors and is absolutely new and confidential in terms of its scientific value.

\section{References}

1. Anderson, B. Spector, A. Introduction to Pilates-based rehabilitation. Orthopedic Physical Therapy clinics of North America.

2. Anderson, K.G. \& Behm, D.G. 2005. The impact of instability resistance training on balance and stability. Sports Medicine. 35(1): 43-53.

3. Bhattacharya, P. 2005. Implication of an Aging Population in India: Challenges and Opportunities.

4. Behm, D.G. \& Anderson, K.G. 2006. The role of instability with resistance training. Journal of strength and conditioning Research. 20(3): 716-722.

5. Beaudreau, S., Adam P. Spira, Anita Stewart, Eric J. Kezirian, Li- Yung Lui, Kristine Ensurd, Susan Redline, Sonia Ancoli- Israel and Katie L. 2012. Validation of the Pittsburgh Sleep Quality Index and the Epworth Sleepiness Scale in Older Black and White Women. Sleep Med. 13 (1): 36-42.

6. Bethards, et. al. 1995. Intrarater test- retest reliability of an instrument used to measure back and leg strength. Isokinetic and Exercise Science. 5 (1): 31-35.

7. Behm, D. Eric J. Drinkwater, Jeffrey M. Willardson and Patrick M. Cowley. 2010. Canadian society for exercise physiology position stand: The use of instability to train the core in athletic and non-athletic conditioning. Applied physiology, nutrition \& metabolism. 35(1): 109-112.

8. Behm D, Anderson K, Curnew S. 2002. Muscle force and neuromuscular activation under stable and unstable conditions. Journal of strength condition Research. 16(3): 416-422.

9. Curnow, D., Cobbin, D., Wyndham, J. \& Boris Choy, S.T. 2009. Altered motor control, posture and the Pilates method of exercise prescription. Journal of Bodywork and Movement Therapies. 13(1): 104-111.

10. Caldwell, K. Harrison, M. Trovis Triplett, N. 2009. Effect of Pilates and Taiji quan training on self efficacy, sleep quality, mood \& physical performance of college students. Journal of Bodywork and Movement Therapies. 13(2): 155-163.

11. Caroline Stretton Nancy K Latham Kristte N Carter Arier C Lec Craig S Anderson. 2006. Determinants of Physical health in frail older people: The important of Self-efficacy.

12. Dite, W. Viviene A. Temple. 2002. A Clinical Test of Stepping and Change of Direction to Identify Multiple Falling Older Adult. Archives of Physical Medicine and Rehabilitation. 83.
13. Donahoe- Fillmore B, Hanahan N, Mescher M, Clapp D, Addison N, Westan C. 2007. The effects of a home Pilates program on muscle performance and posture in healthy females: a pilot study. Journal of Women Health Physical Therapy. 31: 6-11.

14. Engelhorn, R. 1983. Agonist and antagonist muscle EMG activity pattern changes with skill acquisition. Research Quarterly for exercise and Sport. 4: 315-323.

15. Granacher, Urs, Muehlbauer, T., Gruber, M. 2012. A Qualitative Review of Balance and Strength Performance in Healthy Older Adults: Impact for Testing and Training. Journal of Aging Research.

16. Holviala J., Kraemer W. J., Sillanpaa E., Karppinen H., Avela J., Kauhanen A., Hakkinen A., Hakkinen K. 2012. Effects of strength, endurance and combined training on muscle strength, walking speed and dynamic balance in aging men. European Journal of Applied Physiology. 112: 1335-1347.

17. Claude P. Hobeika. 1998. Equilibrium and balance in the elderly. ENT- Ear, Nose \& Throat journal. 78 (8): 558-566.

18. Heitkamp HC, Horstmann T, Mayer F, Weller J, Dickhuth HH. 2001. Gain in strength and muscular balance after balance training. International Journal of Sports Medicine. 22(4): 285-290.

19. Johnson, E. Larsen, A. Kennedy, K. L. 2007. The effects of Pilates based exercise on dynamic balance in healthy adults. Journal of Bodywork and Movement Therapies. 11(3): 238-242.

20. Krems, C., Luhrmann, P., \& Neuhauser-Berthold, M. 2004. Physical activity in young and elderly subjects. Journal of Sports Medicine and Physical Fitness. 44(1): 71-76.

21. Kloubec, June A. 2010. Pilates for improvement of muscle endurance, flexibility, balance and posture. Journal of Strength \& Conditioning Research. 24(3): 661-667.

22. Marks, R. 1992. The effect of aging and strength training on skeletal muscle. Australian Journal of Physiotherapy. 38 (1): 9-19.

23. Magnusson, SP. Simonsen, EB. Aagaard, P. Sorensen H. and Kjaer, M. 1997. A mechanism for altered flexibility in human skeletal muscle. The journal of Physiology. 497(1): 291-298.

24. Nitz, J., \& Choy, N. 2004. The relationship between ankle dorsiflexion range, falls and activity level in women aged 40-80 years. New Zealand Journal of Physiotherapy. 32(3): 121-125.

25. Pober, D., Freedson, P., Kline, G., McInnis, K., \& Rippe, J. 2002. Relationship of age to selected fitness and health related measures in healthy adults ages 4079 years. Clinical Exercise Physiology. 4(2): 108-119.

26. Rhonda O. Nathan J. de Vos, Nalin A. Singh, Dale A. Ross, Theodora M. Stavrinos, and Maria A. FiataroneSingh. 2006. Power Training Improves Balance in Healthy Older Adults. Journal of Gerontology: Medical Sciences. 61A (1): 78-85.

27. Rodrigues, B. Cader, S. Dantas, E. 2010. Pilates method in personal autonomy, static balance and quality of life of elderly females. Journal of Bodywork and Movement Therapies. 14(2): 195-202.

28. Rogol, I. Ernst, G. Perrin, D. 1998. Open and closed kinetic chain exercises improve shoulder joint 
reposition sense equally in healthy subjects. Journal of Athletic Training. 33(4): 315-318.

29. Rogers K. and Gibson, A. 2009. 8-weeks traditional mat Pilates training program effects on adult fitness characteristics. Research Quarterly for exercise and Sport. 3: 569-574.

30. Susan L. Whitney, Gregory F. Marchetti, Laura O. Morris, Patrick J. Sparto. 2007. The Reliability and Validity of the Four Square Step Test for People with Balance Deficits Secondary to a Vestibular Disorder. Archives of Physical Medicine and Rehabilitation. 88.

31. Spira, A. Sherry A. Beaudreau, Katie L. Stone, Eric J. Kezirian, Li-Yung Lui, Susan Redline, Sonia AncoliIsrael, Kristine Ensurd and Anita Stewart. 2012. Reliability and Validity of the Pittsburgh Sleep Quality Index and the Epworth Sleepiness Scale in Older Men. J Gerontol A Biol Sci Med Sci. 67 A (4): 433-439.
32. Soderman, K. Werner, S. Pietila, T. Engstom, B. Alfredson, H. 2000. Balance board training: prevention of traumatic injuries of lower extremities in female soccer players. Knee Surgery, Sports Traumatology, Arthroscopy. 8(6): 356-363.

33. Sekendiz B, Altun O, Korkusuz F, Akm S. 2007. Effects of Pilates exercise on trunk strength, endurance and flexibility in sedentary adults females. Journal of Bodywork and Movement Therapies. 11: 318-326.

34. Verhagen, E.A.L.M., Tulder, M., Beek, A.J., Bouter, L.M. \& Mechelen, W. 2005. An economic evaluation of a proprioceptive balance board training programme for the prevention of ankle sprains in volleyball. British Journal of Sport Medicine. 39(2): 111-115.

35. Verhagen, E.A.L.M. Tulder, M. Beek, A.J. Bouter, L.M. and Mechelen W. An economic evaluation of a proprioceptive balance board training programme for the prevention of ankle sprains in volleyball. British Journal of Sports Medicine. 2005, 39(2): 111-115.

36. Vera- Garcia F, Grenier S, Mc Gill S. Abdominal muscle response during curl-ups on both stable and labile surfaces. Journal of Physical Therapy. 2000; 80(6): 564-569.

\section{How to cite this article:}

Monika Rani et al (2017) ' Does Exercises Improve Sleep Quality, Balance And Strength Among Females', International Journal of Current Advanced Research, 06(04), pp. 3509-3514.

DOI: http://dx.doi.org/10.24327/ijcar.2017.3514.0305 